\title{
Lower limb skin loss: simple outpatient management with meshed skin grafts with immediate mobilization
}

\author{
S. SHANKAR \& C. T. K. KHOO \\ Accident and Emergency and Plastic Surgery Departments, Wexham Park Hospital, \\ Slough, Berkshire, England
}

\section{SUMMARY}

Traumatic skin loss is a common problem in elderly patients presenting to an accident and emergency department.

The authors report their experience with 25 patients in whom pretibial wounds were debrided, and covered with skin grafts taken under local anaesthetic and meshed by hand. All were immediately mobilized and discharged home. Healing was satisfactory in every case and there were no complications.

All the patients found the treatment acceptable, and were delighted to avoid admission to hospital. This is a simple and effective outpatient procedure which can readily be carried out in the accident and emergency department.

\section{INTRODUCTION}

Elderly patients often suffer lower limb lacerations, and commonly present to the accident and emergency department with flaps of crushed and contused skin over the tibia. The authors' treatment of this condition routinely involved admission to the Plastic Surgery ward for debridement and skin grafting in the operating theatre, followed by bedrest in hospital until the skin grafts were well established.

Sharpe et al. (1983) pointed out that skin grafts in the lower limb could successfully be mobilized immediately. The authors have confirmed this observation, and extended the use of the technique to the casualty theatre where it has also proved effective. No special facilities are required and patients who would otherwise have been admitted were allowed home immediately after treatment.

Correspondence: $\mathrm{Mr}$ S. Shankar, Consultant in Accident and Emergency Medicine, Bedford General Hospital (South Wing), Kempston Road, Bedford, Bedfordshire MK42 9DF, England 


\section{METHOD}

The operations were all carried out by one surgeon (SS) in the Accident and Emergence. Departments of Wexham Park Hospital, and Northampton General Hospital, England

All loose or contused tissue was excised from the pretibial wound until viable, freelf bleeding tissue was encountered. This was sometimes at the level of the subcutaneous fat (Fig. 1) and sometimes at the level of the fascia (Fig. 2). The depths of the woun $\overline{\bar{A}}$ were cleaned with a moist saline swab and any further non-viable tissue was excised Any large bleeding vessels were ligated, but no other attempts were made to securf haemostasis. The size of the defect was assessed and a moist swab was laid over th $\vec{s}$ wound whilst the skin graft was being taken.

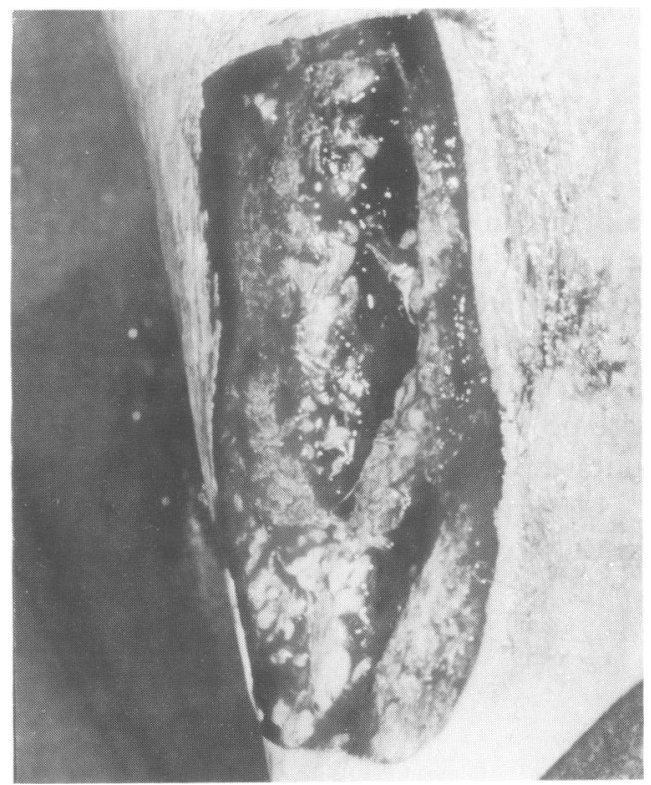

Fig. 1 Defect debrided down to vascularized fat.

The outer aspect of the same thigh was cleaned, and an appropriately sized donor sice infiltrated subcutaneously with $15-20 \mathrm{ml} 0.5 \%$ plain lignocaine. A medium thicknes్ split skin graft (Fig. 3), slightly larger in area than the size of the wound, was taken and was wrapped in a moist swab. The donor site was dressed with tulle gras, dry gauze, cotton wool and a crepe bandage.

The piece of skin graft was spread on a wooden board and meshed by hand using a no. 15 blade (Fig. 4). The graft was applied to the raw area (Fig. 5) and the small piece $\overline{\mathrm{Qt}}$ excess skin was trimmed away and stored in the refrigerator in a sterile container for later use, if necessary. The grafted wound was covered with tulle gras. No margin sutures were used. The graft was adequately secured with a firm pressure dressing. Tw8 layers of tubigrip were then applied to the limb to cover both donor and recipient sites.

The patient was allowed home with instructions to keep the limb elevated whe possible but normal mobility about the house was permitted. 


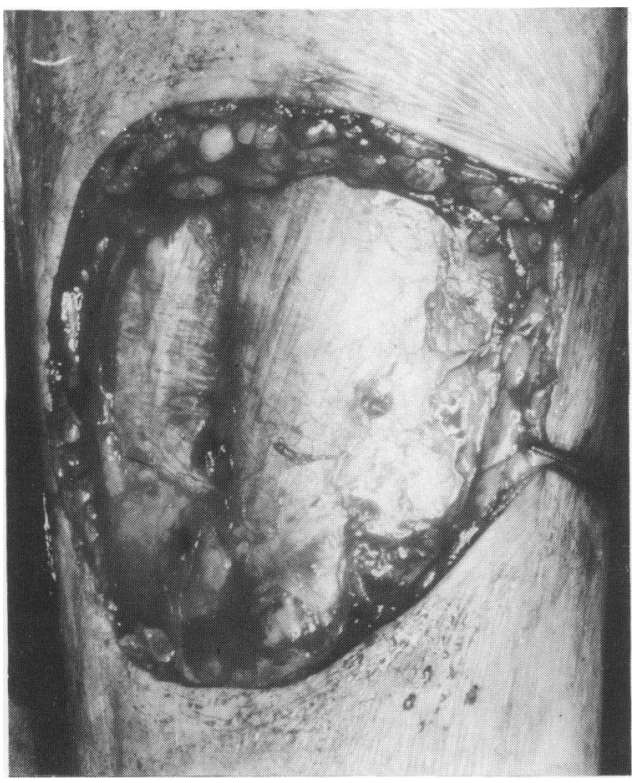

Fig. 2 Defect debrided down to fascia.

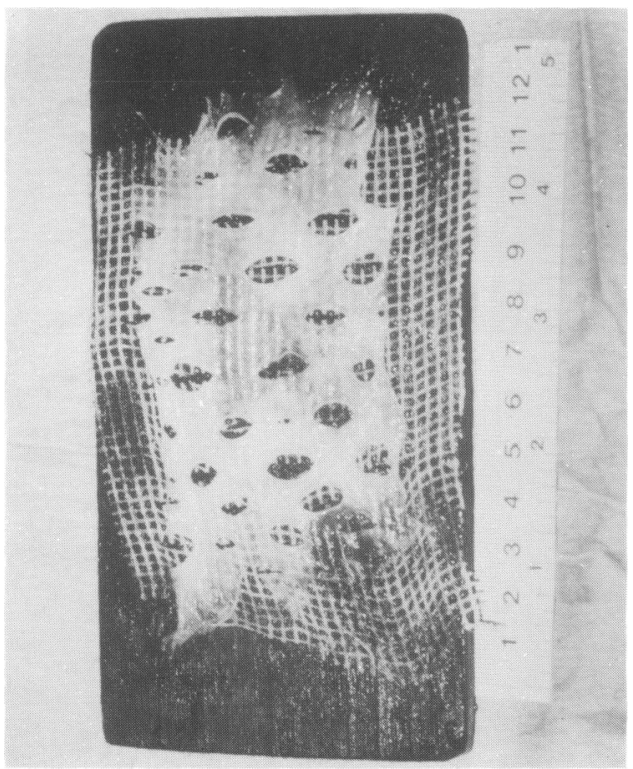

Fig. 4 Split skin graft meshed with scalpel blade.

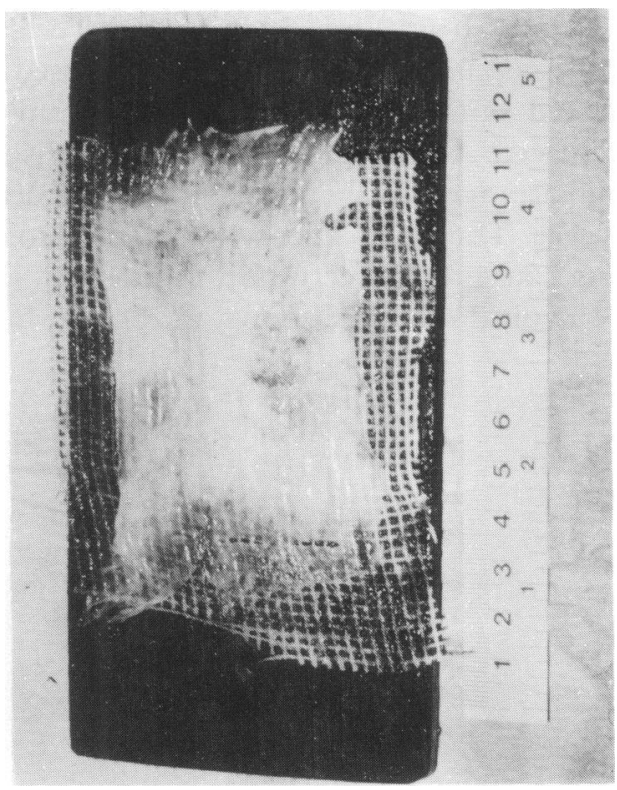

Fig. 3 Split skin graft spread on board.

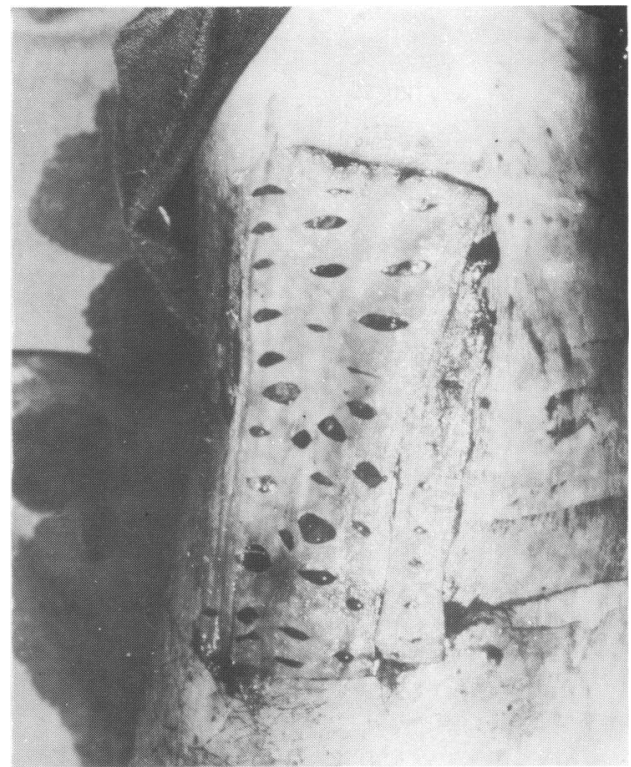

Fig. 5 Split skin graft applied to defect. 
The skin graft was reviewed at a week and photographed. Any haematoma which ha्d collected under the graft was expressed through the holes in the mesh and addition stored skin applied if necessary to any small raw areas. The pressure dressing w\$ renewed. At this stage, patients were discharged to the care of their general practitione荫 and arrangements were made for the district nurse to remove the donor site dressing at weeks. The district nurse was invited to discuss or refer back to the patient if there wås any cause for concern but, in practice, all skin grafts had taken by the third week.

Typical cases are shown in Fig. 6a, b \& c, and Fig. 7a \& b.
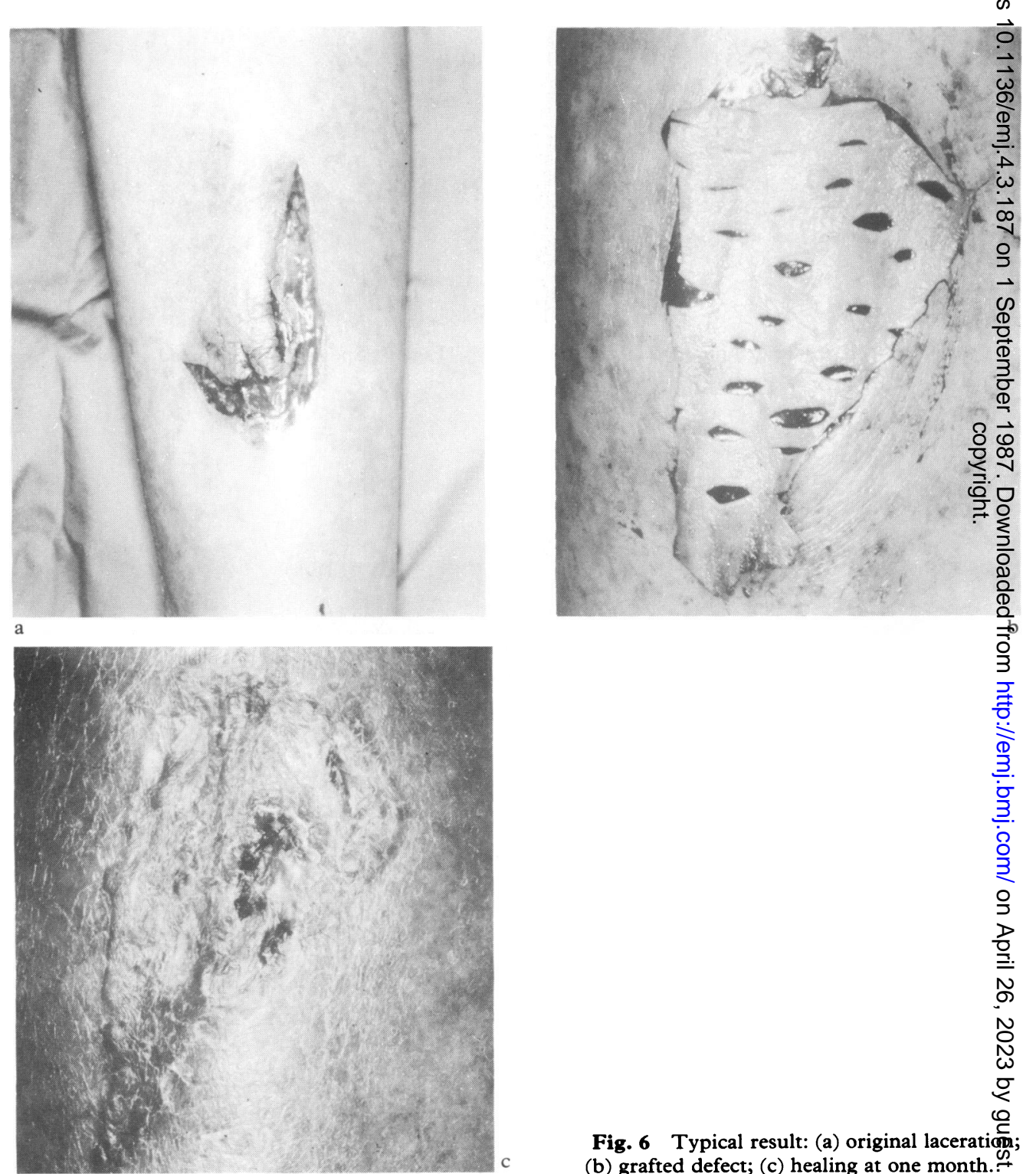

Fig. 6 Typical result: (a) original laceration; (b) grafted defect; (c) healing at one month.? 

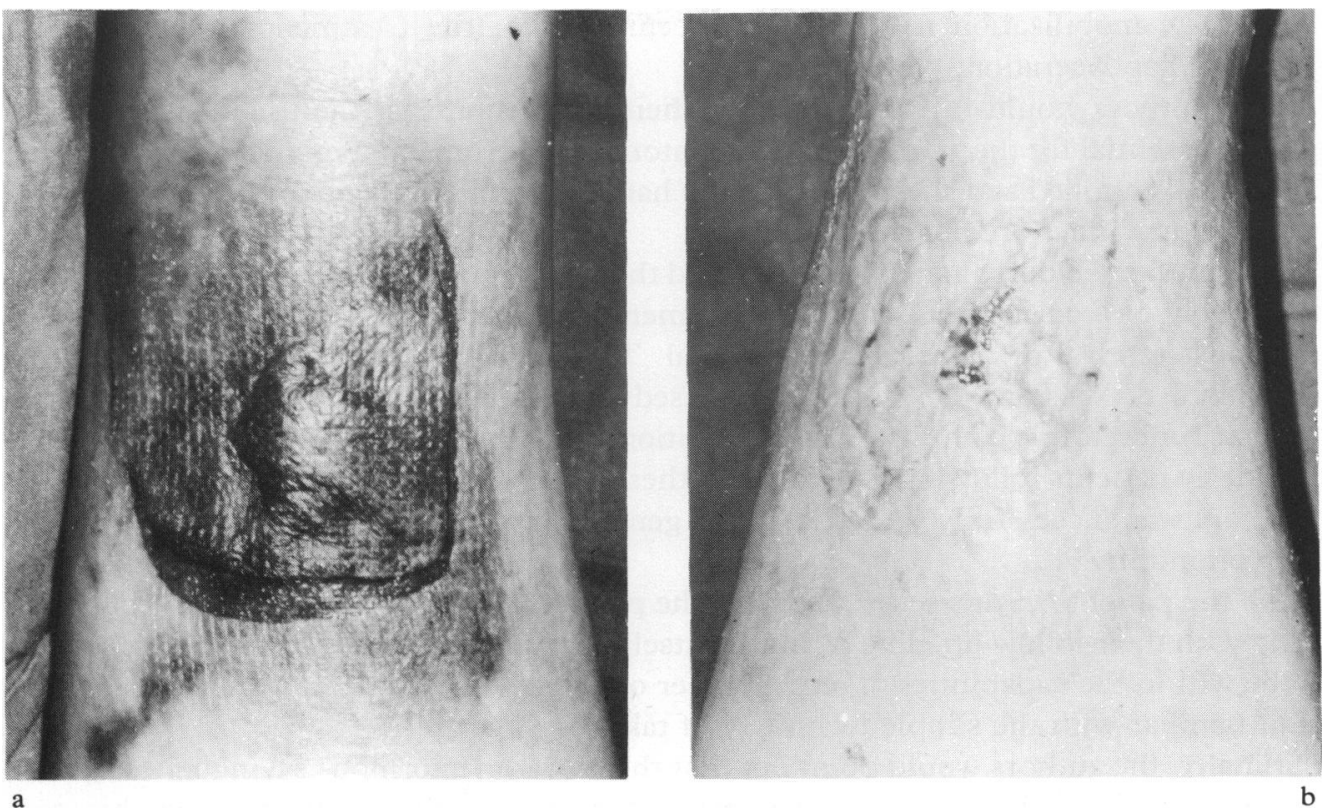

Fig. 7 Typical result: (a) original laceration; (b) healing at one month.

\section{RESULTS}

The average age of the 25 patients (one bilateral case) in this study was 75 years and the patients ranged in age from 48 to 92 years.

Local anaesthesia was used in all cases and two patients were given a small dose of intravenous diazepam because of initial anxiety about the procedure, which was then completed with their full cooperation. All the patients were interviewed later about their reactions to the procedure and there were no objections to this manner of treatment. All the patients stated that they were pleased to be able to go home immediately after treatment.

All grafts were judged to be soundly healed at 3 weeks. Twenty-three out of 25 patients achieved $100 \%$ initial skin graft take, whilst very small areas of loss were treated by the application of stored skin graft in the other patients. Surface redness of the graft was usual from the first to the third week but this appearance did not indicate any compromise of graft viability. All wounds and donor sites were completely healed when finally reviewed one month after treatment.

\section{DISCUSSION}

Sharpe and his co-workers (1983) have already shown within the context of a specialized plastic surgery department that meshed skin grafting under local anaesthetic with 
immediate mobilization is an effective technique for the treatment of the commog pretibial flap laceration.

The authors would fully concur with their conclusion that the use of meshed ski禺 graft is essential for the avoidance of haematoma and seroma that might compromise the take of skin applied as a sheet. Meshing by hand was successful, and sophisticated skinmeshing machines are not needed.

The authors' elderly patients all tolerated the procedure cheerfully and well, and wer effectively treated in the Accident and Emergency Department without the need fo 8 specialist referral or admission to hospital. The physical risks of venous thrombosi (Ramnani \& Weston, 1980) were decreased by the immediate mobilization and nळ patient suffered this complication. In addition, the possibility of mental disorientation in elderly patients following general anaesthesia and admission to hospital was avoided and care was successfully shared with the general practitioner and the district nurse in the community.

All the patients in this series tolerated the procedure well and were able to cooperate fully with their follow up. The technique itself is straightforward and the authors feel i卬 to be within the capabilities of any member of an accident and emergency departmeng staff familiar with the simple technique of taking a skin graft.

Finally, the authors would point out that there was an enormous saving in the cost o 5 operating-theatre time and bed occupancy for each of these patients and this $\cos \frac{\mathbb{D}}{\square}$ effectiveness is another factor which makes this technique well worthwhile.

\section{ACKNOWLEDGEMENTS}

We thank Miss M. S. Christian and Dr R. G. Daniels, Consultants in Charge of th Accident and Emergency Departments at Wexham Park and Northampton Genera侱 Hospitals for their support in this project.

We are grateful to the Medical Illustration Departments of both hospitals an especially to Mrs Jean Tyler of Wexham Park Hospital for photographing our patients

\section{REFERENCES}

Ramnani S. R. \& Weston P. A. M. (1980) Early grafting under regional anaesthesia as an outpatient procedure. Injury 12, 360-4.

Sharpe D. T., Cardoso E. \& Baheti V. (1983) The immediate mobilisation of patients with lower limb skip grafts: a clinical report. British fournal of Plastic Surgery 36, 105-9. 